\title{
Field Evidence of Inverse Energy Cascades in the Surfzone
}

\author{
STEVE Elgar AND BRITT RAUBENHEIMER \\ Woods Hole Oceanographic Institution, Woods Hole, Massachusetts
}

(Manuscript received 24 December 2019, in final form 19 April 2020)

\begin{abstract}
Low-frequency currents and eddies transport sediment, pathogens, larvae, and heat along the coast and between the shoreline and deeper water. Here, low-frequency currents (between 0.1 and $4.0 \mathrm{mHz}$ ) observed in shallow surfzone waters for 120 days during a wide range of wave conditions are compared with theories for generation by instabilities of alongshore currents, by ocean-wave-induced sea surface modulations, and by a nonlinear transfer of energy from breaking waves to low-frequency motions via a two-dimensional inverse energy cascade. For these data, the low-frequency currents are not strongly correlated with shear of the alongshore current, with the strength of the alongshore current, or with wave-group statistics. In contrast, on many occasions, the low-frequency currents are consistent with an inverse energy cascade from breaking waves. The energy of the low-frequency surfzone currents increases with the directional spread of the wave field, consistent with vorticity injection by short-crested breaking waves, and structure functions increase with spatial lags, consistent with a cascade of energy from few-meter-scale vortices to larger-scale motions. These results include the first field evidence for the inverse energy cascade in the surfzone and suggest that breaking waves and nonlinear energy transfers should be considered when estimating nearshore transport processes across and along the coast.
\end{abstract}

\section{Introduction and observations}

In the surfzone, low-frequency (several-minute period) currents and eddies transport sediment, pathogens, larvae, pollutants, heat, and bacteria along the coast and between the shoreline and deeper water (Boehm 2003; Grant et al. 2005; Cowen et al. 2006; Halpern et al. 2008). Horizontal velocity fluctuations with frequencies as low as a few millihertz have been observed (MacMahan et al. 2004, 2010) and numerically simulated (Reniers et al. 2007; Long and Özkan-Haller 2009; Geiman and Kirby 2013; Uchiyama et al. 2017) in surfzones on a range of ocean beaches. Recently, extension of previous analyses to an order-of-magnitude lower frequency (Elgar et al. 2019) suggests the low-frequency motions have a peak near $f \sim 0.5 \mathrm{mHz}$, where $f$ is frequency. For example, low-frequency horizontal currents of order $0.1 \mathrm{~m} \mathrm{~s}^{-1}$ were observed in the surfzone near Duck, North Carolina (Fig. 1, the sensor was located at crossshore coordinate $=260$, alongshore coordinate $=780 \mathrm{~m}$, Fig. 2), during a 24-h period with nearly constant offshore (5-m water depth) significant wave height $H_{\text {sig }}$ (4 times the standard deviation of sea surface-elevation

Corresponding author: Steve Elgar, elgar@whoi.edu fluctuations, $\left.H_{\text {sig }} \sim 1.5 \mathrm{~m}\right)$ and period $(\sim 10 \mathrm{~s}, f \sim$ $100 \mathrm{mHz})$, wave directions within $5^{\circ}$ of normal incidence, small mean currents, and $0.6 \mathrm{~m}$ tidal amplitude (Fig. 1a).

The observations in Fig. 1 are from 1 sensor in an array of 36 wave and current gauges (Fig. 2) that were deployed for 120 days (August-November 1997), allowing low-frequency currents to be investigated for a range of conditions. The bathymetry was nearly alongshore homogeneous (Fig. 2 and Feddersen and Guza 2003).

\section{Hypotheses}

Low-frequency waves can be generated on the continental shelf (Gill and Schumann 1974) and propagate into the surfzone. Here, the power in the low-frequency band suggests the currents do not exist outside the surfzone and increase in strength onshore of the region of wave breaking (Fig. 3), implying generation in the surfzone, not on the continental shelf.

There are several hypotheses for the generation of low-frequency motions in the surfzone. Low-frequency currents have been observed on bathymetrically alongshoreinhomogeneous beaches, including those with one or more 

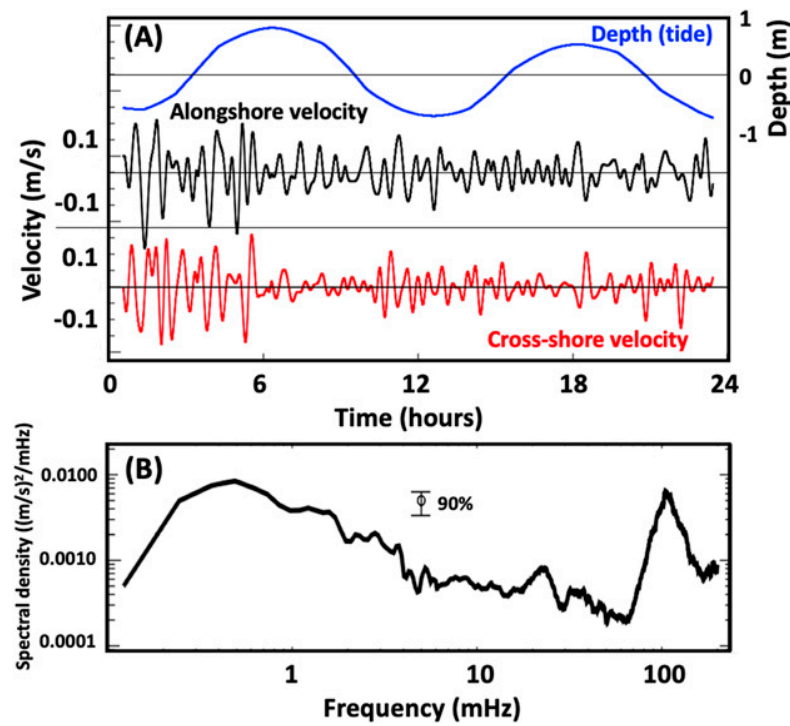

FIG. 1. (a) Low-pass $(f<4 \mathrm{mHz})$ de-meaned cross-shore (red curve, mean $\sim 0.00 \mathrm{~m} \mathrm{~s}^{-1}$ ) and alongshore (black curve, mean $\sim 0.04 \mathrm{~m} \mathrm{~s}^{-1}$ ) velocity (left-hand vertical axes) and tidal elevation (blue curve, right-hand vertical axis) vs time and (b) the sum of the cross-shore plus alongshore velocity power spectral densities vs frequency for observations obtained at the sensor located at $X=260, Y=780 \mathrm{~m}$ (Fig. 2) on 14 Nov 1997. Eight 3-h-long records were detrended to remove tidal fluctuations and averaged to estimate spectral levels with 20 degrees of freedom.

rip channels (MacMahan et al. 2004; Castelle et al. 2010), and theoretical and numerical simulations of waves propagating across rip-channeled surfzone bathymetry often include low-frequency motions (Johnson and Pattiaratchi 2006; Kennedy et al. 2006; Reniers et al. 2007; Geiman and Kirby 2013; Uchiyama et al. 2017). On alongshore uniform beaches, low-frequency velocity fluctuations have been hypothesized to be generated by instabilities of the alongshore current (Bowen and Holman 1989; Oltman-Shay et al. 1989; Özkan-Haller and Kirby 1999). For the 120 days of data analyzed here, the power in the low-frequency band (estimated as the integral of the spectrum for $0.1<f<4.0 \mathrm{mHz}$ for each 24-h-long data run beginning at midnight) was not correlated with the cross-shore gradient of the alongshore current, $d V / d x$, where $V$ is alongshore current and $x$ is cross-shore distance (Fig. 4, the mean alongshore currents for the data shown in Fig. 1 were close to 0 ). The relationship of low-frequency power with the maximum alongshore current (colors in Fig. 4) is similar to that with $d V / d x$, possibly because active shear waves tend to smooth velocity gradients (Noyes et al. 2004).

Numerical simulations suggest that slow modulations of the sea surface (e.g., wave groups) can generate

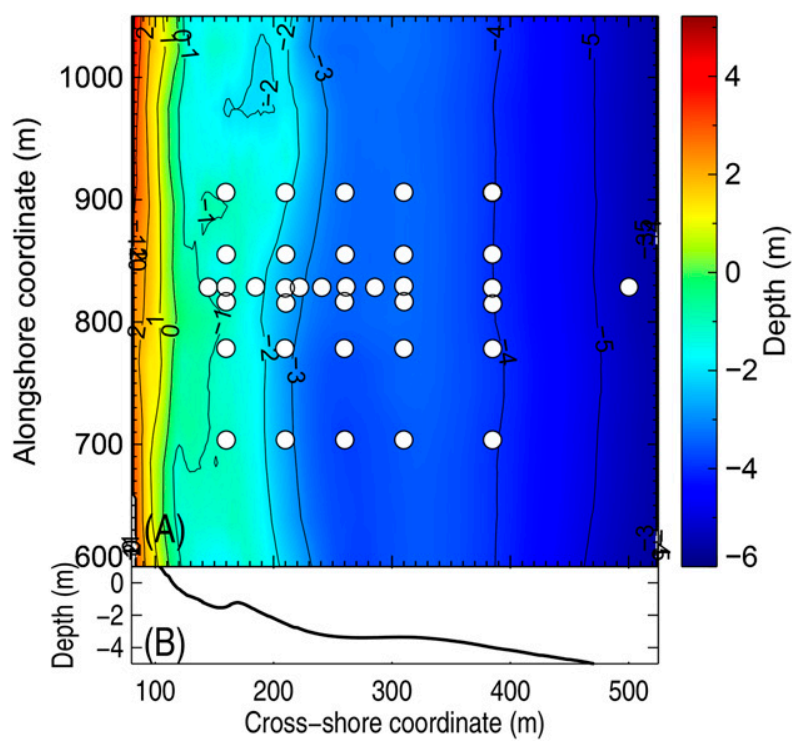

FIG. 2. (a) Bathymetry [color scale on the right and curves every $1 \mathrm{~m}$ are depth relative to North American Vertical Datum of 1988 (NAVD 88), similar to mean sea level] as a function of cross-shore and alongshore coordinates, and (b) depth vs cross-shore coordinate along a transect at alongshore coordinate $\sim 830 \mathrm{~m}$. White circles in (a) are locations of colocated wave and current sensors.

low-frequency motions in the surfzone (Haller et al. 1999; Long and Özkan-Haller 2009; MacMahan et al. 2010; and many others). Once they are spun up, the lowfrequency motions might continue as they slowly decay

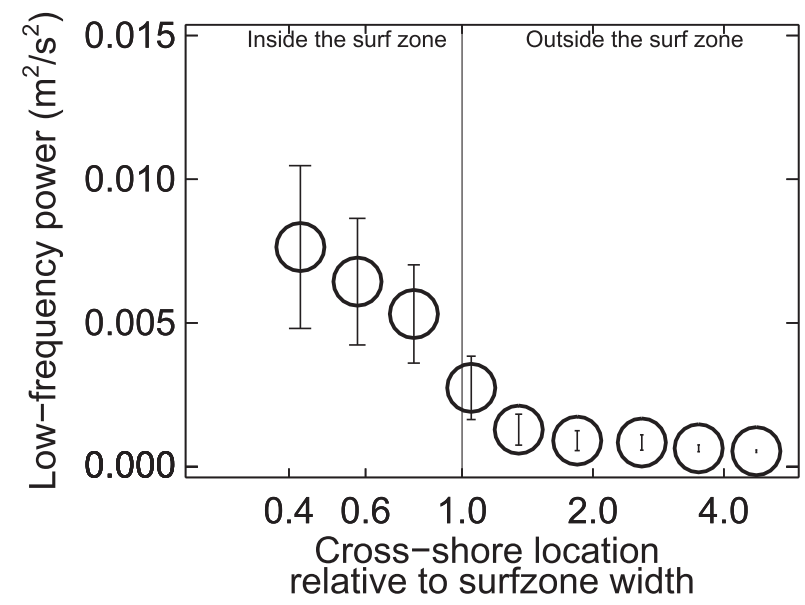

FIG. 3. Power in the low-frequency band $(0.1<f<4.0 \mathrm{mHz})$ vs cross-shore location relative to the cross-shore coordinate (Fig. 2) where waves begin to break, defined as the location where energy flux is less than $85 \%$ of the energy flux measured in 5-m water depth. The low-frequency power is the average over $24 \mathrm{~h}$, and all sensors in the array for the full dataset are used. The symbols are the mean values within that bin, and the vertical bars are \pm 1 standard deviation. 


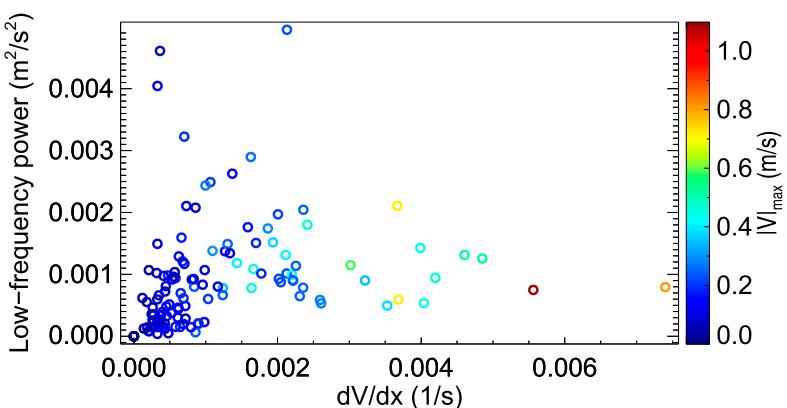

FIG. 4. Maximum (for all sensors) power in the low-frequency band $(0.1<f<4.0 \mathrm{mHz})$ vs the maximum cross-shore gradient of alongshore velocity, $d V / d x$, for every 24 -h run. The correlation is $r=0.2$, which is not statistically different than 0 at the $95 \%$ level. The symbols are colored by the absolute value of the maximum alongshore current for that data point (color scale on the right).

after the forcing by sea surface modulations ends (Long and Özkan-Haller 2009). However, the surfzone is strongly dissipative, and it is unlikely low-frequency eddies remain active for more than one or two turnover times (tens of minutes). Thus, according to this hypothesis the low-frequency currents observed over a $24 \mathrm{~h}$ period would be expected to be correlated with the sea surface elevation fluctuations. However, when converted to velocity using the linear finite-depth dispersion relationship, the sea surface-elevation spectral levels (at all sensors for all the data) within the low-frequency band are two to three orders of magnitude smaller than the sum of the cross- and alongshore spectral levels (lowfrequency pressure spectral levels often were not statistically different than zero), indicating the motions observed here are rotational (Lippmann et al. 1999), and may not be forced directly by patterns in the sea surface. Although some sensors may be located near a node of the pressure signal, it is unlikely that all the sensors are near a node. Also, if wave groups drive the lowfrequency motions, it would be expected that as the wave field becomes more strongly modulated (e.g., more "groupy"), the low-frequency motions would increase. One measure of "groupiness" is the average number of sequential waves greater than a threshold, which is inversely proportional to the width of the sea surfaceelevation power spectrum $S(f)$ (i.e., the sea surface is more strongly modulated for narrowband wave fields) (Cartwright and Longuet-Higgins 1956; Goda 1970; Elgar et al. 1984; and many others). A spectral width parameter $\mu_{2} / m_{2}$, where $\mu_{2}=\int_{50 \mathrm{mHz}}^{200 \mathrm{mHz}}\left(f-f_{c}\right) S(f) d f$ and $m_{2}=\int_{50 \mathrm{mHz}}^{200 \mathrm{mHz}} f^{2} S(f) d f$, are the second moment about the centroid $f_{c}$ of the wind-wave spectrum $S(f)$ and the second moment of $S(f)$, respectively, often is used to investigate wave group statistics (Cartwright and

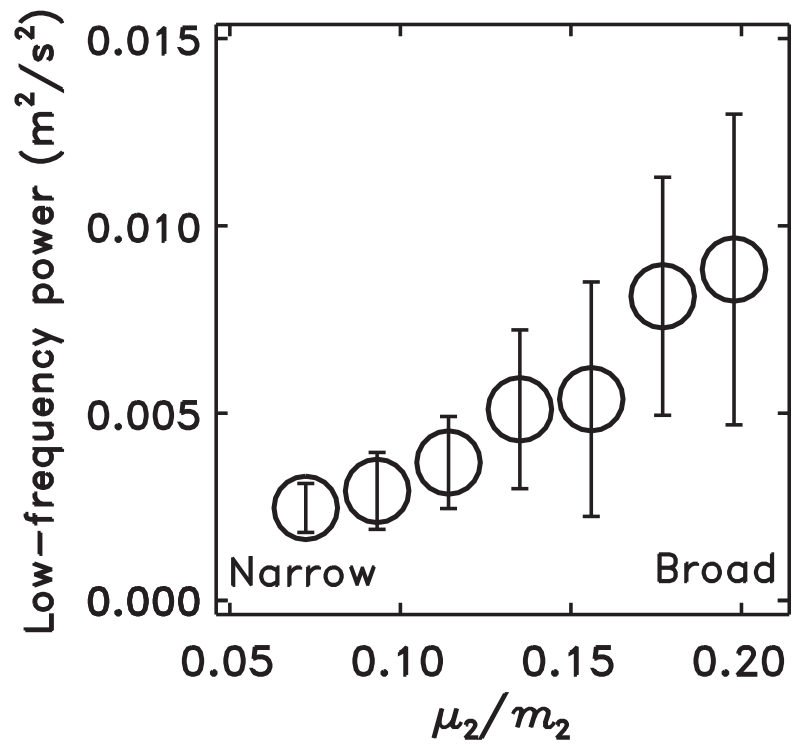

FIG. 5. Power in the low-frequency band $(0.1<f<4.0 \mathrm{mHz})$ at each sensor in the array vs the width of the offshore (5-m water depth) sea surface-elevation spectrum in the wind-wave frequency band $(50<f<200 \mathrm{mHz})$. The low-frequency power is the average over $24 \mathrm{~h}$, and all sensors in the array for the full dataset are used. The symbols are the mean values within that bin, and the vertical bars are \pm 1 standard deviation. Using the spectral width estimated at each sensor does not change the results significantly.

Longuet-Higgins 1956; Goda 1970; Elgar et al. 1984; and many others). The width parameter increases as the spectrum broadens, and thus groupiness decreases as $\mu_{2} / m_{2}$ increases. For the data considered here, on average the low-frequency power decreases as the wave field becomes more narrow-banded (i.e., more groupy) (Fig. 5), suggesting that the low-frequency currents are not always driven by slow modulations of the sea surface.

An additional hypothesis for the generation of lowfrequency surfzone motions is via a nonlinear transfer of energy from high-frequency, small-scale motions induced by breaking waves to lower-frequency, larger motions (Peregrine 1998; Spydell et al. 2007; Spydell and Feddersen 2009; Feddersen 2014). Theoretically, high-frequency, few-meter-scale vorticity is generated in the surfzone by short-crested breaking waves (Peregrine 1998; Bühler 2000; Bonneton et al. 2010). In agreement with theory, numerically simulated shortcrested breaking waves generate vorticity (Bühler 2000; Johnson and Pattiaratchi 2006), with vorticity variance increasing with the number of crest ends, which increase with increasing directional spread (Spydell et al. 2007, 2009; Spydell and Feddersen 2009; Feddersen 2014; Spydell 2016; Wei et al. 2017). Here, directional spread 


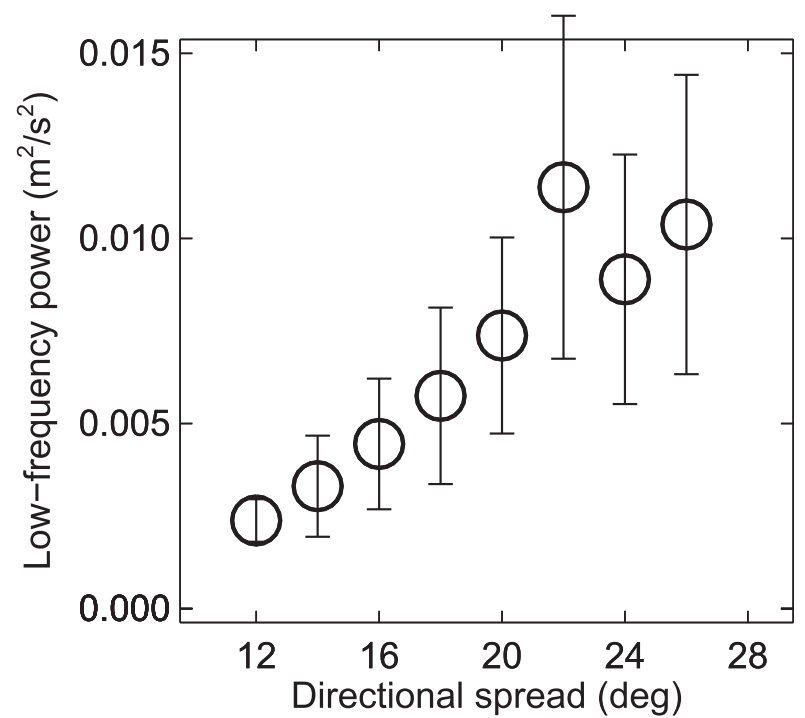

FIG. 6. Power in the low-frequency band $(0.1<f<4.0 \mathrm{mHz})$ at each sensor in the array vs directional spread in the offshore (5-m water depth) wind-wave frequency band $(50<f<$ $200 \mathrm{mHz}$ ). The low-frequency power is the average over $24 \mathrm{~h}$, and all sensors in the array for the full dataset are used, except for those 24-h periods for which the offshore-wave directional spread varied by more than $10 \%$ over the 24 -h period. The symbols are the mean values within that bin, and the vertical bars are \pm 1 standard deviation.

is estimated from velocity time series using the energyweighted $(50<f<200 \mathrm{mHz}$, the wind-wave band) Fourier coefficients for the directional distribution that are not corrupted by reflecting waves (Kuik et al. 1988). Consistent with the theoretical and numerical results showing a transfer of energy from breaking-wave-injected vorticity to lower-frequency currents, the power of lowfrequency motions increases with increasing directional spread of the waves (Fig. 6). There also are more crest ends for wave fields with broad power spectra, consistent with the increase of low-frequency motions as the widths of the power (Fig. 5) and directional spectra (Fig. 6) increase. The results are not significantly different using the spread estimated for the offshore (5-m water depth) waves or the spread estimated at each sensor in the array.

For the shallow water depths in the surfzone, eddies with horizontal scales greater than a few meters can be considered two-dimensional (2D), possibly becoming quasi-2D in the deeper water near the outer edge of the surfzone where there is evidence for weak vertical structure in higher-frequency nearshore eddies (Lippmann et al. 2016; Henderson et al. 2017). In contrast to three-dimensional turbulence, two-dimensional flows have an inverse cascade where energy from stirring at small scales is transferred to larger scales (Kraichnan 1967;
Tabeling 2002; Boffetta and Ecke 2012). Thus, forcing at small length scales, as expected from short-crested breaking waves, can be a source of the lower-frequency, larger-scale motions that are correlated with mixing in shallow water.

To test this hypothesis, structure functions, which have been used to investigate a range of two-dimensional flows (Smith and Yakhot 1994; Boffetta et al. 2000; Kellay and Goldburg 2002), were estimated from the arrays of current meters (Fig. 2). The second-order structure function $S$ is defined as $S(\Delta y)=\left\langle[v(y+\Delta y)-v(y)]^{2}\right\rangle$, where $v$ is the current in the $y$ (either cross- or alongshore) direction, $\Delta y$ is the spacing (lag) between measurement locations, and angle brackets $\langle\cdot\rangle$ indicate time averaging. In an inverse energy cascade, $S \sim(\Delta y)^{2 / 3}$ for length scales greater than (frequencies less than) those of the forcing (Smith and Yakhot 1994; Boffetta et al. 2000; Kellay and Goldburg 2002), which are here hypothesized to be the ends of short-crested breaking waves.

Structure functions estimated from one 24-h-long observational period (Fig. 1) for each of the 5 alongshore arrays and for the cross-shore array (alongshore coordinate $830 \mathrm{~m}$, Fig. 2) are proportional to $(\Delta y)^{2 / 3}$ (Fig. 7), consistent with the hypothesis of a transfer of energy from short-crested breaking waves to lower-frequency currents (Peregrine 1998; Spydell et al. 2007; Spydell and Feddersen 2009; Feddersen 2014). Subdividing the 24-hlong time series into smaller sections does not change the results, although, as expected the structure functions are noisier with fewer observations.

Structure functions were calculated for the alongshore and cross-shore arrays for all data runs meeting quality control criteria. For the 120 twenty-four-hour-long data runs analyzed here, 22 did not have sufficient numbers of sensors operating continuously to estimate structure functions (at least four sensors, providing six spatial lags), and 31 did not have significant low-frequency power (at least twice the noise level), usually owing to low-energy waves. Of the 31 low-energy data runs, 22 had offshore energy (proportional to $H_{\text {sig }}^{2}$ ) $<0.36 \mathrm{~m}^{2}, 4$ had $0.36<$ energy $<0.49 \mathrm{~m}^{2}$, and 5 had $0.49<$ energy $<$ $0.81 \mathrm{~m}^{2}$. For the largest offshore waves $\left(H_{\text {sig }}^{2}>\sim 2.5 \mathrm{~m}^{2}\right)$ several alongshore arrays were in the surfzone for the full $24 \mathrm{~h}$ (e.g., Figs. 1 and 7), whereas for smaller offshorewave conditions, only the shallower arrays were in the surfzone. Data from the shallowest array $(x=160 \mathrm{~m}$ in Fig. 2) were used only when all sensors remained submerged (thus, excluding runs with spring low tides). Similarly, structure functions were estimated along the cross-shore array when there were a sufficient number of sensors in the surfzone. Thus, for the 67 twentyfour-hour-long runs meeting the quality control criteria, there are 131 estimates of structure functions along the 


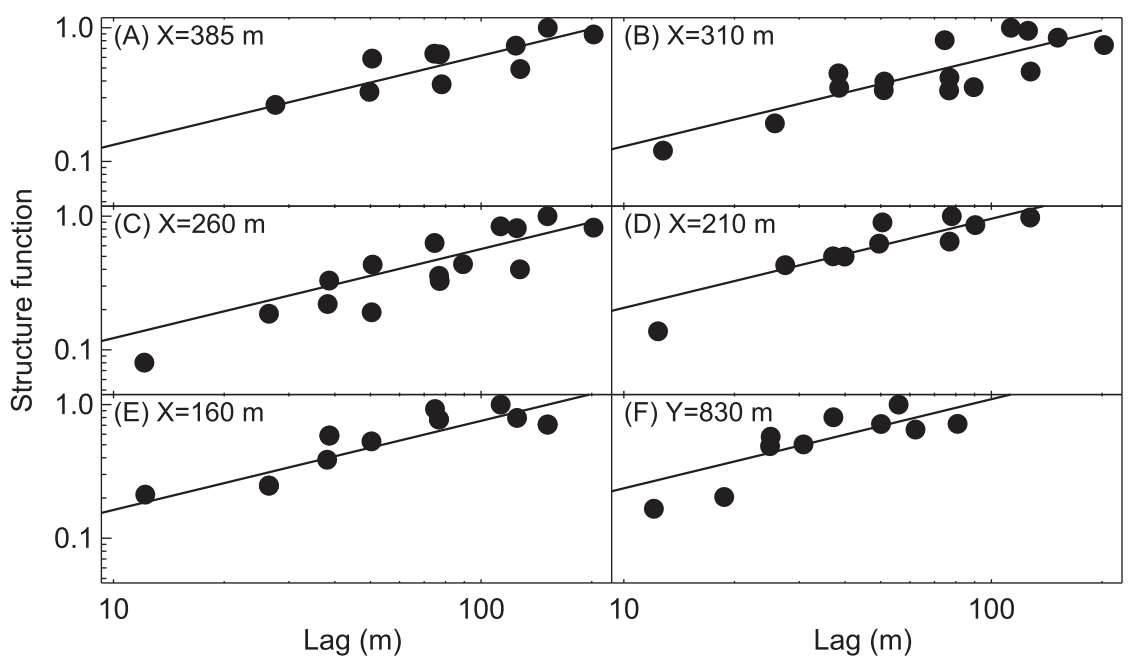

FIG. 7. Second-order structure function (normalized by the maximum value for that array) vs lag from alongshore arrays located at cross-shore coordinate $X=$ (a) 385 , (b) 310 , (c) 260 , (d) 210 , and (e) $160 \mathrm{~m}$, and from the cross-shore array located at alongshore coordinate $Y=830 \mathrm{~m}$ (Fig. 2). No outliers were discarded, but not all sensors were operational for the full 24-h-long data run, and thus some arrays have fewer symbols than other arrays. Alongshore velocities are used for the structure functions estimated with observations from the alongshore arrays in (a)-(e), and cross-shore velocities are used for the structure function estimated with observations from the cross-shore array in (f). The lines are least squares fits to $\mathrm{Clag}^{2 / 3}$, where $C$ is a constant, the value expected for a $2 \mathrm{D}$ turbulent inverse energy cascade. The data are from the 24-h-long run starting at midnight on 14 Nov 1997.

alongshore arrays (using alongshore velocity), and there are 38 estimates of cross-shore structure functions along the cross-shore array (using cross-shore velocity). On average, the structure functions satisfy $S \sim(\Delta y)^{2 / 3}$, consistent with an inverse energy cascade (Fig. 8).

Although the spatial scale of short-crested breakingwave-induced vorticity is not known, numerical experiments suggest it is on the order of $10-30 \mathrm{~m}$, increasing as directional spread decreases (Spydell et al. 2007; Spydell and Feddersen 2009). At spatial scales smaller than the scales of the injected vorticity, the $2 \mathrm{D}$ energy cascade is such that enstrophy (the integral of vorticity squared) is transferred to smaller-scale motions, where it is dissipated (Smith and Yakhot 1994; Boffetta et al. 2000; Kellay and Goldburg 2002). The second-order structure function for the enstrophy cascade is $S \sim(\Delta y)^{2}$. Thus, to avoid the enstrophy cascade region, observations for the few lags less than $\sim 20 \mathrm{~m}$ are not included in the fits of the second-order structure function for the energy cascade to $(\Delta y)^{2 / 3}$ (Fig. 8). To investigate the energy and enstrophy cascades for a wider range of spatial scales, and to estimate the spatial scales of breakingwave-induced vorticity, an alongshore array with sensors spaced logarithmically from 2 to $256 \mathrm{~m}$ is planned for deployment in the surfzone in the future. In theory, the scale of the injected vorticity can be estimated from the scale for which the energy $\left[S \sim(\Delta y)^{2 / 3}\right]$ and enstrophy $\left[S \sim(\Delta y)^{2}\right]$ structure functions cross (Spydell and Feddersen 2009).

\section{Conclusions}

Low-frequency $(0.1<f<4.0 \mathrm{mHz})$ horizontal surfzone currents were investigated with arrays of current meters and pressure gauges deployed for 120 days on a long, straight Atlantic Ocean beach. On average, the lowfrequency current power estimated over 24-h periods

- is weak outside the surfzone;

- is not strongly correlated with cross-shore gradients in mean alongshore currents or with the maximum alongshore velocity;

- increases as the sea surface-elevation spectrum broadens, the opposite of the expectation if modulations of the sea surface (e.g., wave groups) drive these motions;

- increases as the directional spread of the wave field increases;

- is consistent with an inverse energy cascade that transfers energy from breaking-wave-induced vorticity to lower-frequency motions.

Thus, although instabilities of sheared alongshore currents and groups of ocean waves may produce eddies with periods of a few minutes, the observations analyzed here suggest low-frequency surfzone currents also may be at 


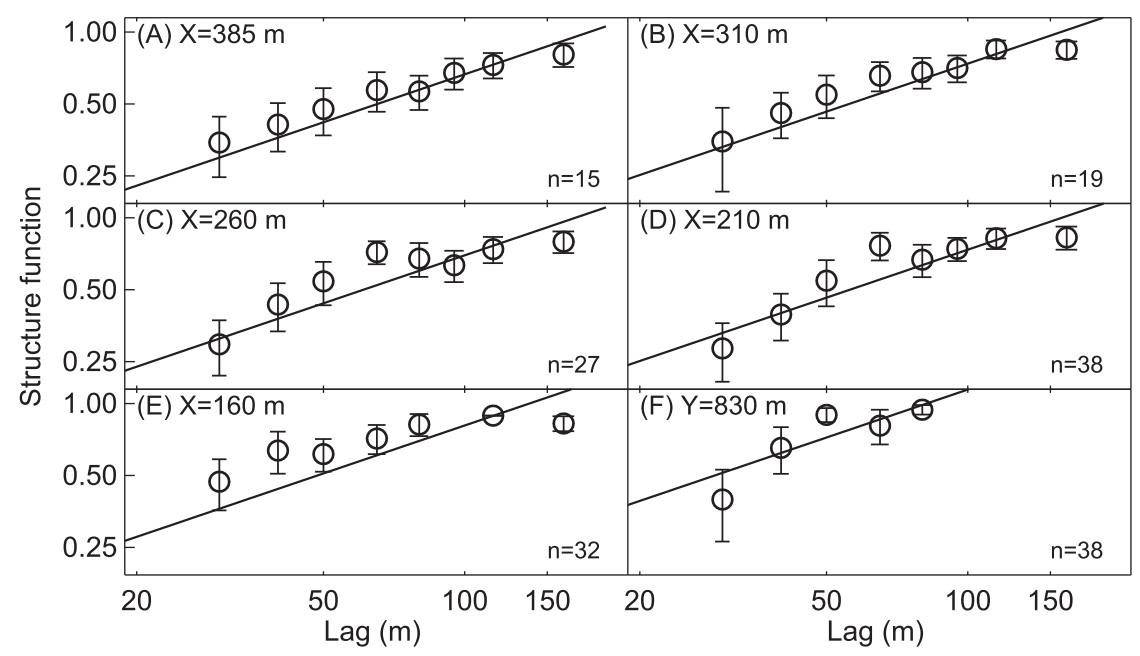

FIG. 8. Second-order structure function (normalized by the maximum value for that array) vs lag from alongshore arrays located at cross-shore coordinate $X=$ (a) 385, (b) 310, (c) 260, (d) 210, and (e) $160 \mathrm{~m}$, and from the cross-shore array located at alongshore coordinate $Y=830 \mathrm{~m}$ (Fig. 2). Alongshore velocities are used for the structure functions estimated with observations from the alongshore arrays in (a)-(e), and cross-shore velocities are used for the structure function estimated with observations from the cross-shore array in (f). Structure functions for 24-h data runs during which the low-frequency power was above $0.001 \mathrm{~m}^{2} \mathrm{~s}^{-2}$ (statistically significantly above twice the noise at the $95 \%$ level) and for which at least four sensors (thus, at least six spatial lags) were operating were estimated at each array. The number $(n)$ of 24-h data runs that satisfied the criteria at each array are listed in the lower-right corner of each panel. The lines are least squares fits to $C \mathrm{lag}^{2 / 3}$, where $C$ is a constant, the value expected for a 2D turbulent inverse energy cascade.

least partially driven by nonlinear transfers of energy injected into the water column by the ends of breaking waves in a two-dimensional inverse cascade.

Acknowledgments. We thank R. Guza and T. Herbers for their leadership roles during the fieldwork, the CCS (SIO), PVLAB (WHOI), and FRF (USACE) field teams for deploying, maintaining, and recovering sensors in harsh conditions, and the referees for significant and useful suggestions. Funding was provided by a Vannevar Bush Faculty Fellowship [from OUSD(R\&E)] and NSF.

Data availability statement: The 1997 SandyDuck data can be obtained via https://chlthredds.erdc.dren.mil/ thredds/catalog/frf/catalog.html and https:/pv-lab.org.

\section{REFERENCES}

Boehm, A., 2003: Model of microbial transport and inactivation in the surf zone and application to field measurements of total coliform in Northern Orange County, California. Environ. Sci. Technol., 37, 5511-5517, https://doi.org/10.1021/es034321x.

Boffetta, G., and R. Ecke, 2012: Two-dimensional turbulence. Annu. Rev. Fluid Mech., 44, 427-451, https://doi.org/10.1146/ annurev-fluid-120710-101240.

, A. Celani, and M. Vergassola, 2000: Inverse energy cascade in two-dimensional turbulence: Deviations from Gaussian behavior. Phys. Rev. E, 61, R29-R32, https://doi.org/10.1103/ PhysRevE.61.R29.
Bonneton, P., N. Bruneau, B. Castelle, and F. Marche, 2010: Large-scale vorticity generation due to dissipating waves in the surf zone. Discrete Contin. Dyn. Syst., 13B, 729-738, https://doi.org/10.3934/dcdsb.2010.13.729.

Bowen, A., and R. Holman, 1989: Shear instabilities of the mean alongshore current 1. Theory. J. Geophys. Res., 94, 18023 18 030, https://doi.org/10.1029/JC094iC12p18023.

Bühler, O., 2000: On the vorticity transport due to dissipating or breaking waves in shallow-water flow. J. Fluid Mech., 407, 235-263, https://doi.org/10.1017/S0022112099007508.

Cartwright, D., and M. Longuet-Higgins, 1956: The statistical distribution of the maxima of a random function. Proc. Roy. Soc. London, 237A, 212-232, https://doi.org/10.1098/rspa.1956.0173.

Castelle, B., and Coauthors, 2010: Laboratory experiment on rip current circulations over a moveable bed: Drifter measurements. J. Geophys. Res., 115, C12008, https://doi.org/10.1029/ 2010JC006343.

Cowen, R., C. Paris, and A. Srinivasan, 2006: Scaling of connectivity in marine populations. Science, 311, 522-527, https:// doi.org/10.1126/science.1122039.

Elgar, S., R. Guza, and R. Seymour, 1984: Groups of waves in shallow water. J. Geophys. Res., 89, 3623-3634, https://doi.org/ 10.1029/JC089iC03p03623.

—, B. Raubenheimer, D. B. Clark, and M. Moulton, 2019: Extremely low frequency ( 0.1 to $1.0 \mathrm{mHz}$ ) surfzone currents. Geophys. Res. Lett., 46, 1531-1536, https://doi.org/10.1029/2018GL081106.

Feddersen, F., 2014: The generation of surfzone eddies in a strong alongshore current. J. Phys. Oceanogr., 44, 600-617, https:// doi.org/10.1175/JPO-D-13-051.1.

— , and R. Guza, 2003: Observations of nearshore circulation: Alongshore uniformity. J. Geophys. Res., 108, 3006, https:// doi.org/10.1029/2001JC001293. 
Geiman, J., and J. Kirby, 2013: Unforced oscillation of rip-current vortex cells. J. Phys. Oceanogr., 43, 477-497, https://doi.org/ 10.1175/JPO-D-11-0164.1.

Gill, A., and E. Schumann, 1974: The generation of long shelf waves by wind. J. Phys. Oceanogr., 4, 83-90, https://doi.org/ 10.1175/1520-0485(1974)004<0083:TGOLSW>2.0.CO;2.

Goda, Y., 1970: Numerical experiments on wave statistics with spectral simulation. Port and Harbour Research Institute Rep., 57 pp., https://www.pari.go.jp/search-pdf/vol009-no0301.pdf.

Grant, S., J. Kim, B. Jones, S. Jenkins, J. Wasyl, and C. Cudaback, 2005: Surf zone entrainment, along-shore transport, and human health implications of pollution from tidal outlets. J. Geophys. Res., 110, C10025, https://doi.org/10.1029/2004JC002401.

Haller, M., U. Putrevu, J. Oltman-Shay, and R. Dalrymple, 1999: Wave group forcing of low frequency surf zone motion. Coastal Eng. J., 41, 121-136, https://doi.org/10.1142/S0578563499000085.

Halpern, B., and Coauthors, 2008: A global map of human impact on marine ecosystems. Science, 319, 948-952, https://doi.org/ 10.1126/science.1149345.

Henderson, S., J. Arnold, H. Özkan-Haller, and S. Solovitz, 2017: Depth dependence of nearshore currents and eddies. J. Geophys. Res. Oceans, 122, 9004-9031, https://doi.org/10.1002/2016JC012349.

Johnson, D., and C. Pattiaratchi, 2006: Boussinesq modelling of transient rip currents. Coastal Eng., 53, 419-439, https:// doi.org/10.1016/j.coastaleng.2005.11.005.

Kellay, H., and W. Goldburg, 2002: Two-dimensional turbulence: A review of some recent experiments. Rep. Prog. Phys., 65, 845-894, https://doi.org/10.1088/0034-4885/65/5/204.

Kennedy, A., M. Brocchini, L. Soldini, and E. Gutierrez, 2006: Topographically controlled, breaking-wave-induced macrovortices. Part 2. Changing geometries. J. Fluid Mech., 559, 57-80, https://doi.org/10.1017/S0022112006009979.

Kraichnan, R., 1967: Inertial ranges in two-dimensional turbulence. Phys. Fluids, 10, 1417-1423, https://doi.org/10.1063/1.1762301.

Kuik, A., G. Van Vledder, and L. Holthuijsen, 1988: A method for the routine analysis of pitch-and-roll buoy wave data. J. Phys. Oceanogr., 18, 1020-1034, https://doi.org/10.1175/ 1520-0485(1988)018<1020:AMFTRA > 2.0.CO;2.

Lippmann, T., T. Herbers, and E. Thornton, 1999: Gravity and shear wave contributions to nearshore infragravity motions. J. Phys. Oceanogr., 29, 231-239, https://doi.org/10.1175/15200485(1999)029<0231:GASWCT $>2.0$. CO;2.

- E. Thornton, and T. Stanton, 2016: The vertical structure of low-frequency motions in the nearshore. Part I: Observations. J. Phys. Oceanogr., 46, 3695-3711, https://doi.org/10.1175/ JPO-D-16-0014.1.

Long, J., and H. Özkan-Haller, 2009: Low-frequency characteristics of wave group-forced vortices. J. Geophys. Res., 114, C08004, https://doi.org/10.1029/2008JC004894.
MacMahan, J., A. Reniers, E. Thornton, and T. Stanton, 2004: Surf zone eddies coupled with rip current morphology. J. Geophys. Res., 109, C07004, https://doi.org/10.1029/ 2003JC002083.

,$- \longrightarrow$, and — 2010: Vortical surf zone velocity fluctuations with 0(10) min period. J. Geophys. Res., 115, C06007, https:// doi.org/10.1029/2009JC005383.

Noyes, T., R. Guza, S. Elgar, and T. Herbers, 2004: Field observations of shear waves in the surf zone. J. Geophys. Res., 109, C01031, https://doi.org/10.1029/2002JC001761.

Oltman-Shay, J., P. Howd, and W. Birkemeier, 1989: Shear instabilities of the mean longshore current: 2. Field observations. J. Geophys. Res., 94, 18 031-18 042, https://doi.org/10.1029/ JC094iC12p18031.

Özkan-Haller, H., and J. Kirby, 1999: Nonlinear evolution of shear instabilities of the longshore current: A comparison of observations and computations. J. Geophys. Res., 104, 25953 25 984, https://doi.org/10.1029/1999JC900104.

Peregrine, H., 1998: Surfzone currents. Comput. Fluid Dyn., 10, 295-309, https://doi.org/10.1007/s001620050065.

Reniers, A., J. MacMahan, E. Thornton, and T. Stanton, 2007: Modeling of very low frequency motions during RIPEX. J. Geophys. Res., 112, C07013, https://doi.org/10.1029/ 2005JC003122.

Smith, L. M., and V. Yakhot, 1994: Finite-size effects in forced two-dimensional turbulence. J. Fluid Mech., 274, 115-138, https://doi.org/10.1017/S0022112094002065.

Spydell, M., 2016: The suppression of surfzone cross-shore mixing by alongshore currents. Geophys. Res. Lett., 43, 9781-9790, https://doi.org/10.1002/2016GL070626.

_- , and F. Feddersen, 2009: Lagrangian drifter dispersion in the surf zone: Directionally spread, normally incident waves. J. Phys. Oceanogr., 39, 809-830, https://doi.org/ 10.1175/2008JPO3892.1.

,$- \ldots$, R. Guza, and W. Schmidt, 2007: Observing surf-zone dispersion with drifters. J. Phys. Oceanogr., 37, 2920-2939, https://doi.org/10.1175/2007JPO3580.1.

,-- , and - 2009: Observations of drifter dispersion in the surfzone: The effect of sheared alongshore currents. J. Geophys. Res., 114, C07028, https://doi.org/10.1029/2009JC005328.

Tabeling, P., 2002: Two-dimensional turbulence: A physicist approach. Phys. Rep., 362, 1-62, https://doi.org/10.1016/S03701573(01)00064-3.

Uchiyama, Y., J. McWilliams, and C. Akan, 2017: Three-dimensional transient rip currents: Bathymetric excitation of low-frequency intrinsic variability. J. Geophys. Res. Oceans, 122, 5826-5849, https://doi.org/10.1002/2017JC013005.

Wei, Z., R. Dalrymple, M. Xu, R. Garnier, and M. Derakhti, 2017: Short-crested waves in the surf zone. J. Geophys. Res. Oceans, 122, 4143-4162, https://doi.org/10.1002/2016JC012485. 